\title{
ENVIRONMENTAL IMPACTS OF TIDAL POWER SCHEMES
}

\author{
J Wolf*, IA Walkington*, J Holt*, R Burrows^ \\ * Proudman Oceanographic Laboratory \\ $\wedge$ The University of Liverpool, Department of Engineering \\ Contact Dr Judith Wolf e-mail: jaw@pol.ac.uk
}

\begin{abstract}
This paper describes the potential environmental changes caused by tidal power installations with illustration for schemes in the eastern Irish Sea, focussing mainly on major estuarine barrages. The generic impacts in the near-field and far-field are discussed. Results from a 0-D and a 2-D model are presented: the former allows rapid calculations to be made for a large range of options while the latter allows the full effect on $2 \mathrm{D}$ hydrodynamics to be investigated. It is shown that there may be a significant change in tidal amplitude at the coast of Northern Ireland. The bed stress in the Bristol Channel will be significantly reduced if a Severn barrage is constructed. Some effects on the tidal mixing are expected although the location of tidal fronts in the Irish and Celtic Seas will not be changed significantly. The largest environmental impact is expected to be on the amount of inter-tidal area retained after construction of an estuarine barrage. It is shown that the loss of mudflats can be substantially reduced by using a dual-mode (ebb and flood generation) scheme with an increased number of turbines over the lowest-cost option.
\end{abstract}

\section{Introduction}

Any planned tidal barrage (or other coastal and offshore engineering) schemes should be subject to the following considerations (from Elliott et al, 2006): It should be:

- Environmentally sustainable

- Technologically feasible

- Economically viable

- Socially desirable/tolerable

- Legally permissible

- Administratively achievable

- Politically expedient

While many of these points are socio-economic/political and will require public debate and value judgements, here we wish to elucidate the technological and environmental facts related to various options. It has already been demonstrated (Baker, 1991; Burrows et al., 2008) that the locations for the largest procurement of renewable marine energy, whilst still remaining costeffective, are estuaries with a high tidal range utilising barrages. Tidal barrage solutions use established low-head hydropower technology. The tidal power scheme at La Rance scheme in France is now in its $40^{\text {th }}$ year of operation (Pierre, 1993). Thus tidal barrages are technologically feasible. In other areas with large tidal currents (e.g. straits and headlands) there is potential for power-generation using free-standing tidal stream turbines and other schemes using tidal lagoons have been proposed. Burrows et al. (2008) discuss the economic viability, by drawing from the Sustainable Development Commission report on tidal power (SDC, 2007), and they show that major barrages should be economically viable compared to other renewable technologies and can produce a substantial proportion of the UK electricity demand.

Here we review the potential environmental impacts of tidal power schemes in the near and farfields, mainly with respect to tidal barrages. The impacts of the presently proposed tidal current schemes will be minimal and very local to the scheme due to their small power rating: at present 
the maximum power rating mooted is $30 \mathrm{GW}$ (SDC, 2007). Impacts may be beneficial as well as harmful to the environment and some mitigation of potential harmful effects is possible (Gray, 1992). However, in planning any construction, notice must be taken of conservation issues and existing legislation. The European Habitats, Birds and Water Framework Directives are particularly relevant. Many estuaries have some protected status. The only existing scheme at La Rance illustrates some potential impacts e.g. increased muddiness of the seabed and enhanced productivity of the foreshore (Kirby and Retière, 2007). Here we limit the direct investigation to the hydrodynamics but from this other potential environmental impacts are inferred.

From the recent study of the potential tidal power of the eastern Irish Sea (Burrows et al., 2009, this volume), some quantitative results are shown for the combined effects of 5 barrages on NW UK estuaries, using two approaches. The first approach uses a 0-D model in which turbine characteristics and tidal range are considered but not the detailed hydrodynamics. In the second phase of the modelling, a 2-D depth-averaged model (ADCIRC) was employed. This uses an unstructured finite-element grid to model the details of the tidal propagation around the west coast of the UK, with and without tidal barrages. It has high resolution (down to $50 \mathrm{~m}$ ) around the barrage locations. The predicted physical changes in tidal range, residuals, bottom stress and mixing are used to assess the likely environmental and ecological consequences.

\section{Generic Impacts of tidal power schemes}

It has long been recognised that there will be environmental implications in building a tidal barrage e.g. Hodd (1977) and Gordon (1994) discussed impacts for the Bay of Fundy scheme. Baker (1991) and Matthews and Young (1992) review generic environmental impacts for tidal power schemes. Many studies have been carried out in the UK for the Severn Estuary including estimation of impacts on the sediment regime and water quality (Shaw, 1980; Miles, 1982; Odd, 1982; Parker and Kirby, 1982; Radford, 1982; Kirby, 1987; Shaw, 1990) with a recent resurgence of interest (Kirby and Shaw, 2005). BERR (2008) has identified the need for a strategic environmental assessment for the Severn Tidal Power Feasibility Study. This will address the environmental impacts of any chosen scheme on biodiversity and wildlife, flood management, geomorphology, water quality and other issues. In order to assess the present state of the environment and potential impacts, it is desirable to have some quantitative indicators. Aubry and Elliott (2006) describe potential indicators of near shore seabed disturbance which have been grouped into three broad indices (Coastline Morphological Change, Resource Use Change and Environmental Quality and its Perception) and applied to the Humber Estuary. Further work is still needed to refine these methods (Boesch and Paul, 2001). Some information may be obtained from the experience of the existing tidal barrage at La Rance (Kirby and Retière, 2007). For completeness we here list the main local issues which may be of concern with respect to tidal barrages. In the next section we also explore potential far-field impacts.

\subsection{Physical Changes}

By impounding the water for part of the tide there will inevitably be some changes in the estuary basin and channels. The tidal and residual flows will be modified, possibly leading to some local scouring around the structure, specifically in the outflow regions of the turbines and sluices, and siltation in the basin. The amount of vertical mixing will be reduced where the tidal flows are reduced and with less re-suspension the levels of suspended particulate matter will drop, leading to increased light penetration. A reduction in mixing will also lead to an increase in density stratification. There will be reduced saline penetration within the basin leading to freshening i.e. more brackish water. There may be a build-up of contaminants both physical and chemical due to reduced flushing rates. In areas of increased flows there may be potential re-suspension of contaminated sediments. This may result in a net reduction in water quality. An abundance of nutrients combined with increased light availability may lead to increased primary production 
potentially leading to eutrophication. An increase in average water level inside the basin would lead to a decrease in ground water flows which may have impacts on land drainage. All these effects are to a large degree dependent upon the mode of operation of the barrage and are site specific. Various mitigation methods including dredging and more stringent controls on discharges may of course be undertaken.

\subsection{Environmental and ecological impacts}

It must not be overlooked that a benefit of building tidal power plants is to reduce carbon emissions and hence benefit the environment locally and globally. However the most publicised impact of tidal barrages is the potential loss of certain habitats, especially inter-tidal mudflats and salt-marshes. These are particularly important for some species of birds and can be nationally and internationally protected areas. Benthic habitats may change in that the bottom stress due to waves and currents may be modified. Migratory fish may be impeded although fish passes can be constructed. Fish and marine mammals may suffer damage by collision with the barrage and turbines. Some estuaries may provide nurseries for breeding fish and conditions for these may no longer be suitable. An increase in primary productivity may enhance the population of filter feeders.

\subsection{Human, economic, aesthetic and amenity impacts}

The character of an area and the landscape may be drastically changed if a tidal barrage is constructed but in this case there may be pros and cons. Some people may find the visual intrusion objectionable but others may find it adds interest. There may be increased noise especially during construction but also during operation. There may be a loss of historic sites in intertidal areas. However there may also be an increase in tourism and recreational potential of the area. During construction there will be increased demand for resources and potential disruption e.g. road transport may increase, but there will be economic benefits in terms of local jobs.

Shellfish fisheries e.g. cockles and mussels could be affected, although being submerged for longer could be advantageous in giving them more time to filter nutrients from the water (Cesar and Frid, pers. comm.). Cockles are a major prey item for birds and fish and an enhancement of the food supply (see above) may provide the potential for aquaculture. There will be a change in the access for the activities of cockle-pickers. Some coastal land used for agricultural grazing or crops may be lost or more gained. Other activities such as marine transport and navigation may be disrupted but a barrage also gives potential for road and rail crossings

The National Grid is not currently adapted to receive the large pulses of electricity and so some costly re-development and innovative solutions may be necessary.

\section{Tidal Power schemes in the Eastern Irish Sea}

In a recent study we have examined the tidal power potential of the eastern Irish Sea in some detail (Burrows et al., 2008, this volume and http:// www.liv.ac.uk/ engdept/ tidalpower). After the Severn Estuary this area has the highest tidal range in the UK. The area covered is shown in Figure 1, including the estuaries of the Dee, Mersey, Ribble, Morecambe Bay and the Solway Firth, together with contours of the tidal range. Here we examine the specific potential impacts of tidal power schemes in the near and far-fields for this area. For comparison the models have also been extended to include the Severn Estuary as this is well-known to be the largest potential tidal resource in the UK. 


\subsection{Models}

\subsubsection{0-D Model (Generation)}

A 0-D (flat-estuary or two-tank) model has been developed in the project to synthesise barrage operation, with realistic turbine characteristics relating flow rate $\mathrm{Q}$ and power $\mathrm{P}$ to the head $\mathrm{H}$ across the barrage and the variable efficiency (Burrows et al., 2008). Details of this model and results are given in Burrows et al. (this volume). The barrage operation is then simulated using the selected turbine number and characteristics, sluice gate area, delays, estuarial bathymetry and external tide. A prediction of power output and basin level is produced. This provides a useful tool in exploring the potential configuration and operation space of each barrage before modelling in the computationally expensive 2-D model. The presence of a barrage however will inevitably change the tidal range at the barrage site and to model this, the 2-D model is required.

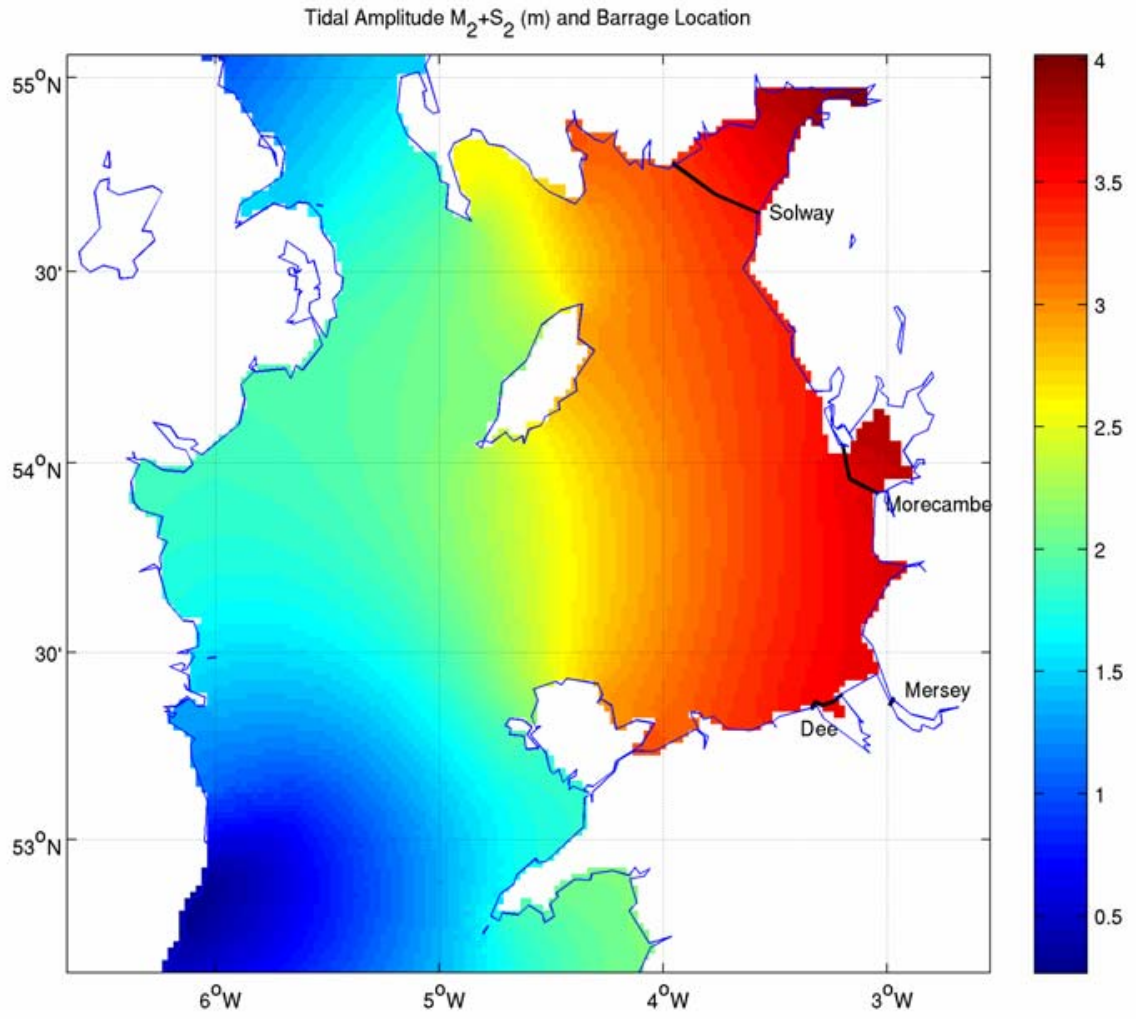

Figure 1 Location of potential tidal barrages in the Eastern Irish Sea. Contours show average spring tide amplitude.

\subsubsection{2-D Model (ADCIRC)}

ADCIRC is a 2-D depth integrated shallow water model which is solved using an unstructured grid approach for the discretisation of the mass equation and the momentum equation, which is formulated in the generalized wave continuity form. The model was developed in the USA (Hench and Leuttich 2003, Leuttich and Westerink 1995) for use in modelling tides and surges on shelf seas. The ADCIRC model allows the simulation of multiple barrage schemes in conjunction to explore their cumulative impact upon the environment and their power production potential and was chosen because it is freely available online. 
Barrages with the same hydraulic characteristics as used in the 0-D model have been inserted into the 2-D model. The objectives of the 2-D modelling, within the recently completed Joule Centre funded project, extend to evaluation of any impact on the overall tidal dynamics of the Irish Sea as a consequence of the energy extraction from the conjunctive operation of the barrages discussed herein (those in the estuaries of the North West of England together with the Severn) as well as potential sites for major tidal stream arrays. Arising from this, implications, if any, from biophysical coupling in the marine ecosystem, manifesting water quality or ecological consequences were to be reviewed (Burrows et al., 2008). Companion studies on the impact of barrage operation on the estuarial sediment regime are currently underway at Liverpool, using a 2-D TELEMAC model of the Dee and Mersey estuary (Carroll et al., 2008).

Due to the nature of the tides off the west coast of the UK the simulated area, as shown in Figure 2 , was very large so as to model the propagation of the tidal waves from deep water over the shelf edge and on into the estuaries of the west coast of the UK. This is especially important in the Bristol Channel and Severn estuary as non-linear resonance effects determine the large tidal amplitude in this estuary (Fong and Heaps, 1978). The unstructured grid permits the resolution to change from a coarse $15 \mathrm{~km}$ in the deep water at the forced open boundary down to $50 \mathrm{~m}$ in
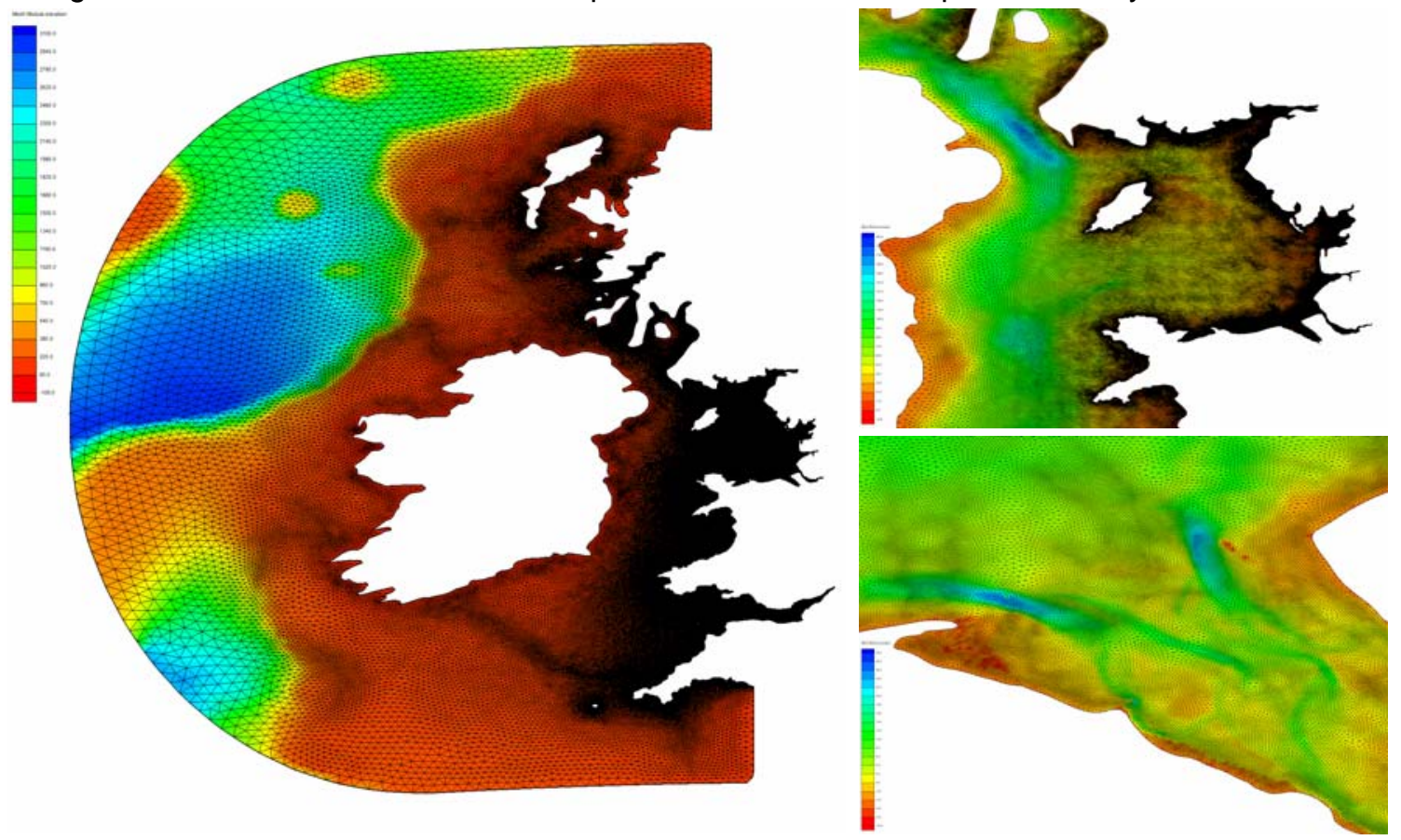

Figure 2 ADCIRC model domain showing increased resolution as the estuaries are approached.

shallow estuaries and near barrage structures. The grid contains almost 400,000 nodes and over 750,000 elements and is solved using 96 processors with a 1 second time step. This takes -24 hours for a 31 day simulation, which includes 1 day spin up and a 15 day settling period and was forced using the 5 major tidal constituents in this region: $\mathrm{M}_{2} ; \mathrm{S}_{2} ; \mathrm{N}_{2} ; \mathrm{O}_{1}$ and $\mathrm{K}_{1}$. The model was first run without barrages, for a baseline state, and then with 5 barrages within the Severn, Dee, Mersey, Morecambe Bay and Solway estuaries.

To validate the model, comparisons were made against tide gauge observations throughout the modelled area. The error estimates of the dominant semi-diurnal $\mathrm{M}_{2}$ and $\mathrm{S}_{2}$ tidal constituents, together with some other models of the same area published recently are shown below in Table 1 and Table 2. 


\begin{tabular}{|l|c|c|c|c|c|}
\hline Error & $\begin{array}{c}\text { ADCIRC vs. } \\
\text { Dataset 1 } \\
(59)\end{array}$ & $\begin{array}{c}\text { ADCIRC } \\
\text { vs. Dataset } \\
2(198)\end{array}$ & $\begin{array}{c}\text { Jones } \\
\text { ADCIRC } \\
(198)\end{array}$ & $\begin{array}{c}\text { Jones } \\
\text { Telemac } \\
(198)\end{array}$ & $\begin{array}{c}\text { POLCOMS } \\
(257)\end{array}$ \\
\hline Amp Mean (cm) & 1.04 & 0.41 & 6.41 & 3.85 & -4.99 \\
\hline Amp RMS (cm) & 9.89 & 10.15 & 17.14 & 23.97 & 14.90 \\
\hline Phase Mean (deg) & 0.30 & 0.29 & -1.07 & 0.28 & -1.00 \\
\hline Phase RMS (deg) & 9.59 & 11.53 & 17.62 & 41.08 & 14.76 \\
\hline $\mathrm{H}_{\mathrm{s}}(\mathrm{cm})$ & 11.09 & 14.42 & 31.50 & 36.05 & 21.61 \\
\hline
\end{tabular}

Table 1 Mean and RMS errors (model minus observation) from a comparison with harmonic analysis of $M_{2}$ from tide gauge data, datasets 1 and 2, around the Irish and Celtic Seas. The Jones models are from Jones et al. (2008) and the POLCOMS model data is taken from Holt et al. (2001) and show the errors associated with these models against comparable observations datasets in the Irish Sea and whole European Shelf respectively.

The value $\mathrm{H}_{\mathrm{s}}$ in the tables is the average difference between the simulated and observed tidal constituent vectors from all the observation locations. The number of observation sites is shown in Table 1 in brackets after the model or dataset name. Dataset 1 was a broad area dataset including locations from the south and the west coasts of Ireland and the larger Dataset 2 was mainly located within the Irish Sea. The tables show that this model is performing well in predicting the tides in the simulated area.

\begin{tabular}{|l|c|c|c|c|c|}
\hline & $\begin{array}{c}\text { Amp Mean } \\
(\mathrm{cm})\end{array}$ & $\begin{array}{c}\text { Amp RMS } \\
(\mathrm{cm})\end{array}$ & $\begin{array}{c}\text { Phase } \\
\text { Mean }\end{array}$ & $\begin{array}{c}\text { Phase } \\
\text { RMS }\end{array}$ & $\mathrm{H}_{\mathrm{s}}$ \\
\hline POLCOMS & -3.83 & 7.64 & 5.31 & 22.55 & 12.04 \\
\hline $\begin{array}{l}\text { ADCIRC vs. } \\
\text { Dataset 1 }\end{array}$ & -1.31 & 3.66 & -1.03 & 11.06 & 4.45 \\
\hline
\end{tabular}

Table 2 Mean and RMS errors (model minus observation) from a comparison with harmonic analysis of $S_{2}$ from tide gauge data, dataset 1 , around the Irish and Celtic Seas. POLCOMS model shows errors associated with this model against comparable observation datasets.

\subsection{Far field effects}

The ADCIRC model has been used to examine large-scale changes in tidal amplitude, bed stress, stratification/mixing and residual flows and hence their implications for sediment transport (without recourse to a detailed sediment transport model), fisheries and other environmental change. Note that here we only examine the tidal residual current, whereas there may also be contributions from wind-driven and buoyancy-driven flows. The direction of bed stress is an indicator of sediment movement as bed load and various regions of convergence and divergence are often in good agreement with locations of sediment deposition. The bedload sediment transport rate is expected to be related to some power of the bed stress. 2D models have been used to examine the spatial distributions of sediments on the northwest European shelf (Pingree and Griffiths, 1979), or in more limited regions (Aldridge, 1997).

The mixing (due to the tidal stirring) and stratification (due to solar heating) of the water column are in balance at the shelf sea tidal mixing fronts, the position of which can be described by the ratio of the total water depth to the cube of a measure of the tidal current strength (Simpson and Hunter, 1974). Convergence and upwelling associated with tidal fronts can be important for the feeding of fish larvae (e.g. Hao et al, 2003). There may be some implications of the movement of the tidal mixing front for Nephrops in the Irish Sea. (Nephrops is also known as scampi, Dublin 
Bay Prawn, or Langoustine.) The Irish Sea Nephrops fishery is the second largest Nephrops fishery for the UK outside the North Sea with reported international landings of 9,120 tonnes in 2007. The majority of the catch is from the western Irish Sea, in an area centred on the location of the tidal mixing front (http://www.cefas.co.uk/media/63515/nephropsirishsea.pdf). Nephrops distribution is limited by the extent of suitable muddy sediment in which they construct burrows. Burrow emergence is known to depend on biological and environmental factors such as ambient light level and tides.

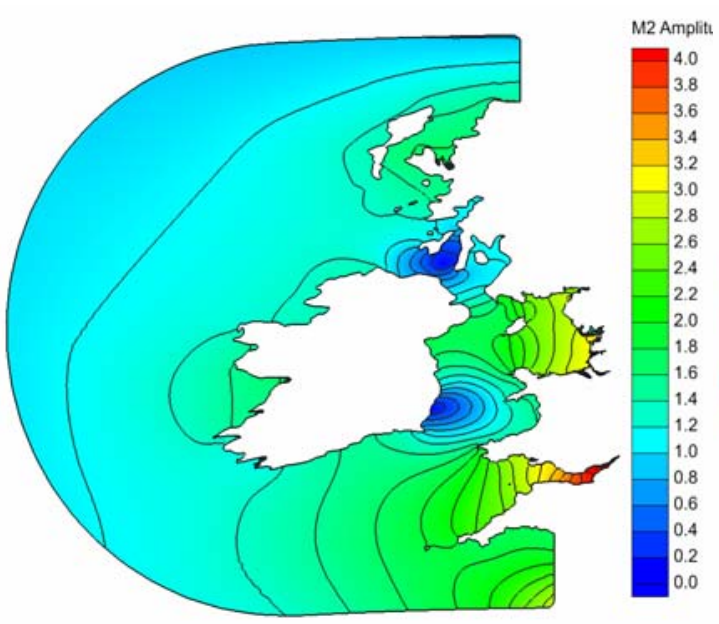

a)

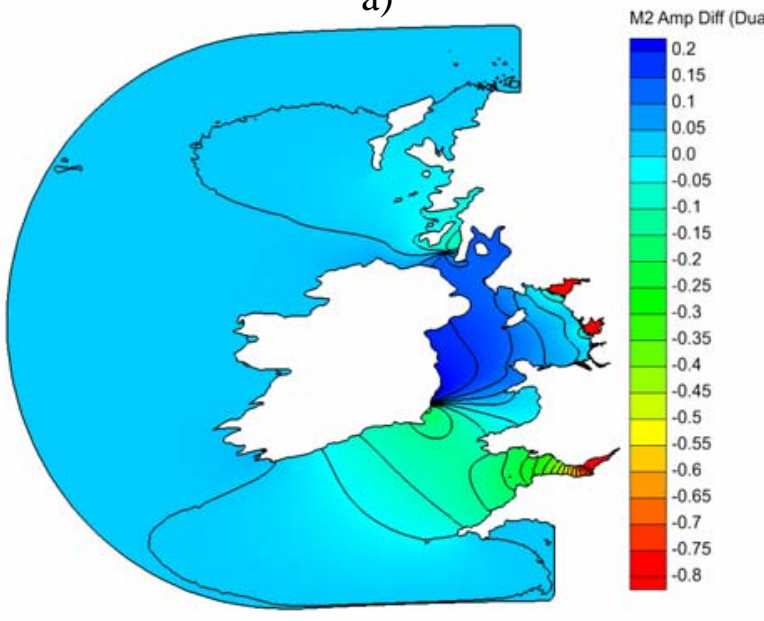

c)

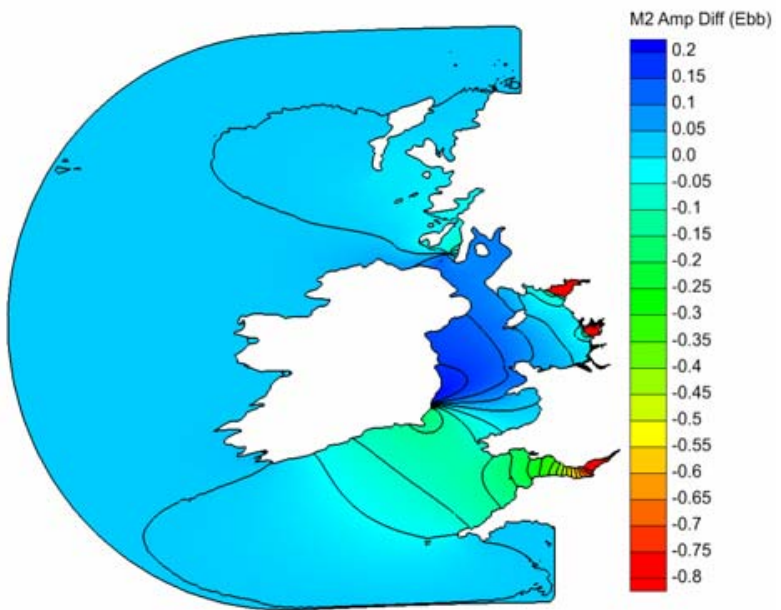

b)

Figure $3 \mathrm{M}_{2}$ tidal amplitude (m) in a) Present situation simulation and $b$ ) difference $(m)$ due to 1x DoEn ebb mode barrage simulation; c) difference due to 3x DoEn dual mode barrage simulation.

Spring-neap frontal migration is generally only a few kilometres (Sharples, 2008). Sharples (2008) also shows that inter-annual changes in the timing of the spring-neap cycle can have a large impact on the primary productivity associated with fronts. The strongest impacts are predicted within $15-50 \mathrm{~km}$ of the tidal mixing fronts, with increases in sub-surface primary production and carbon export. At the fronts, there is substantial extra primary production driven by the springneap cycle, contributing an extra $70 \%$ annually compared to fronts forced by the $\mathrm{M}_{2}$ tide only.

Local changes near headlands, where proposed tidal stream turbines would harness the energy of tidal streams, may affect the location of offshore sandbanks (Pingree and Maddock, 1979; Dyer and Huntley, 1999), which are of considerable economic and ecological importance. Those close to the shore may be linked to beaches in a dynamic exchange of sediment. They may act to dissipate wave energy and thus provide some coastal protection from erosion and wave overtopping but may also be hazards to shipping. They can provide exploitable reserves of sand 
and gravel (marine aggregates). Finally, sand banks are also areas of great importance to the health of the fishing industry, as the banks are important nursery and feeding grounds for many fish species.

\subsubsection{Present Situation}

The present situation throughout the simulated region is initially shown so that the changes introduced by the barrages can be seen in context. The amplitude of the $M_{2}$ tidal constituent is shown in Figure 3 a). The large amplitudes throughout the eastern Irish Sea and in the Bristol Channel are clearly visible, together with the two amphidromic points in this region, one off the east coast of Ireland in the Celtic Sea and the other between the north coast of Northern Ireland and the west coast of Scotland.

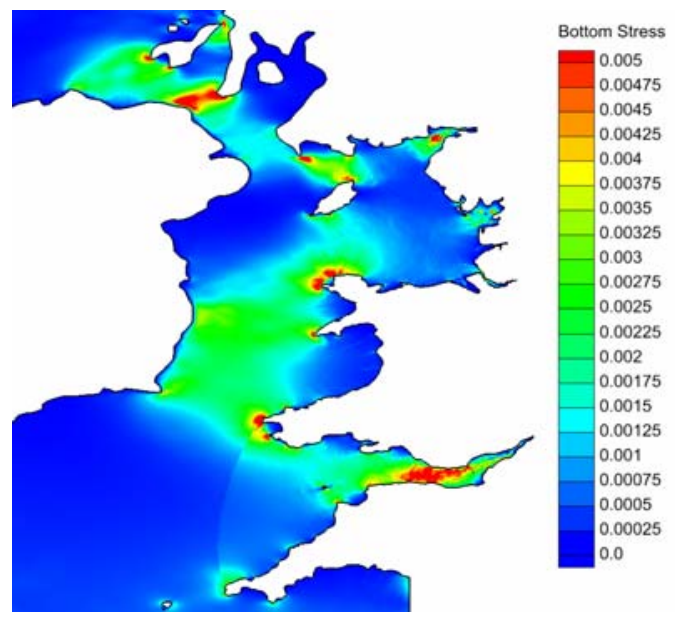

a)

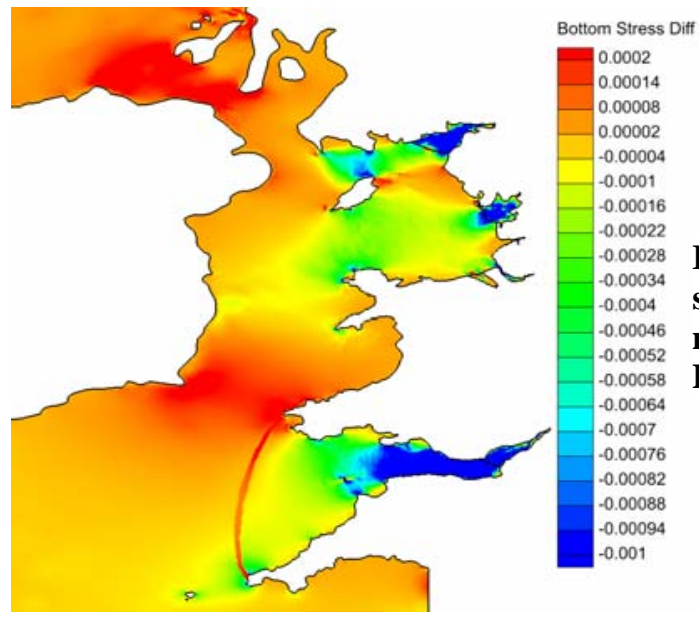

c)

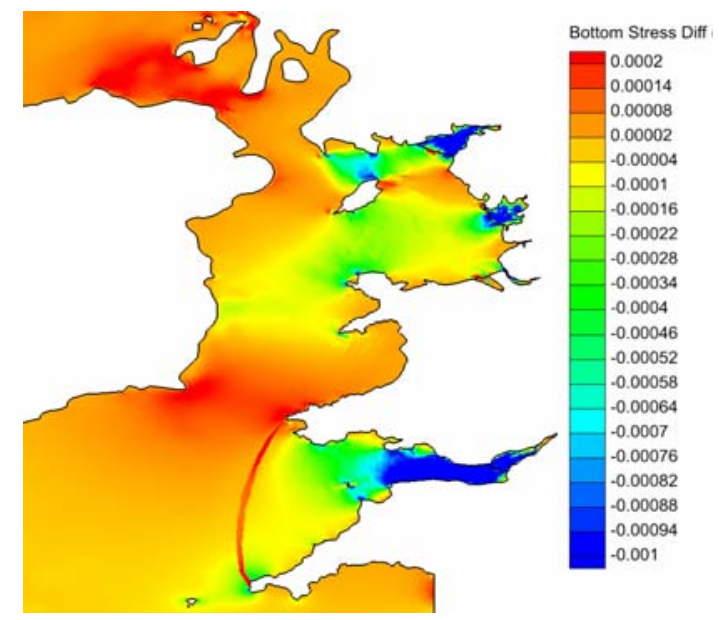

b)

Figure 4 Bottom stress $\left(\mathrm{m}^{2} / \mathrm{s}^{2}\right)$ : a) present situation; b) difference due to $1 x$ DoEn ebb mode simulation; c) difference due to $3 x$ DoEn dual mode simulation.

The maximum $M_{2}$ bottom stress, calculated from $c_{D} \mathbf{u}|\mathbf{u}|$ (where $c_{D}$ is the drag coefficient and $\mathbf{u}$ is the depth-averaged current), is shown in Figure 4a), which reveals the location of the major areas of energy dissipation. The drag coefficient applied in the model is not constant throughout but takes two distinct values with $2 \times 10^{-3}$ everywhere except in the Bristol Channel where it is increased to $3 \times 10^{-3}$ (this was necessary to give a good tidal simulation in the Bristol Channel/Severn Estuary: the position of this change is clearly visible in the bottom stress plot). 
The large bottom stress in the Bristol Channel is the cause of the large amount of suspended sediment in the waters in this area. The large stresses seen off the coasts of West Wales and Northern Anglesey reveal large currents that are both currently proposed areas for tidal stream farms.

The stratification parameter, $\log 10\left(\mathrm{~h} /|\mathrm{u}|^{3}\right)$, gives an indication of the location of tidal mixing fronts when using a 2D depth integrated model. The critical value of $2.7 \pm 0.3$ defines the tidal mixing fronts where the water column changes from stratified to fully mixed (Simpson and Hunter, 1974). Larger values indicate stratified conditions and lower values more well-mixed. The major fronts in the Celtic Sea and the Western Irish Sea are clearly visible in Figure 5a) running from the Southern Irish coast to the North coast of Cornwall and from the Eastern coast of Ireland across to the Isle of Man.

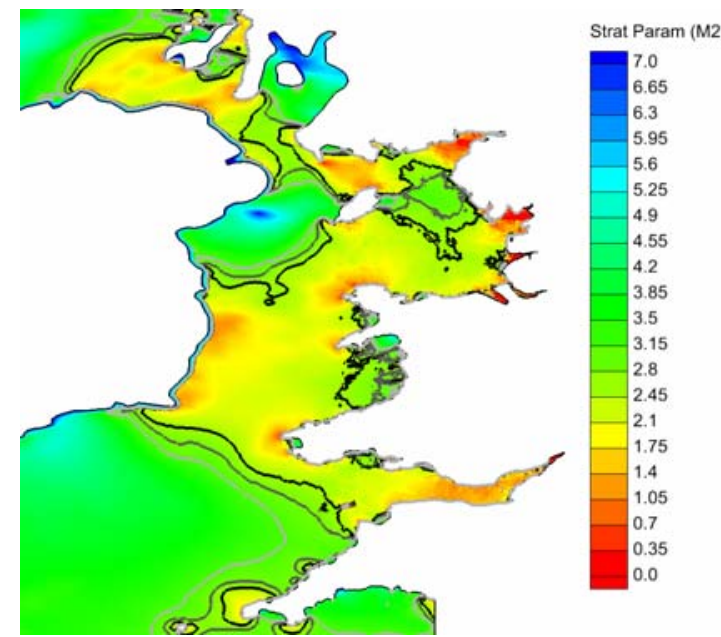

a)

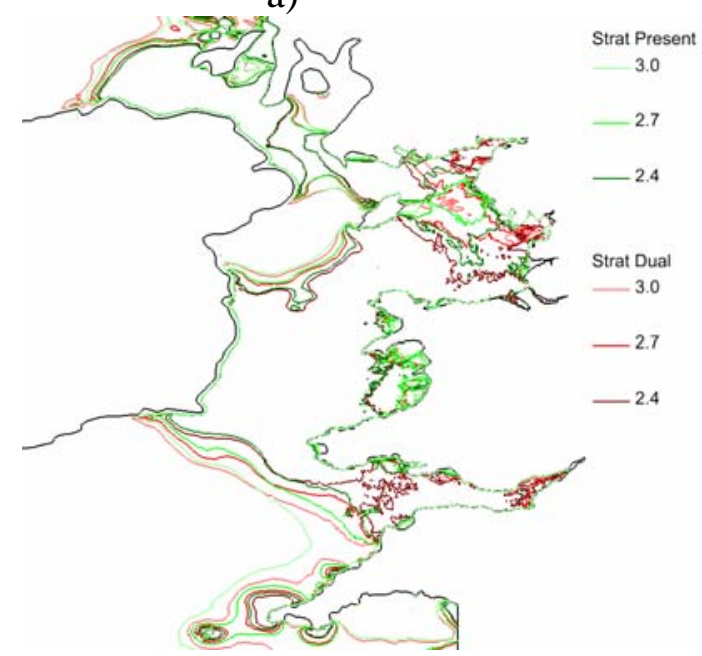

c)

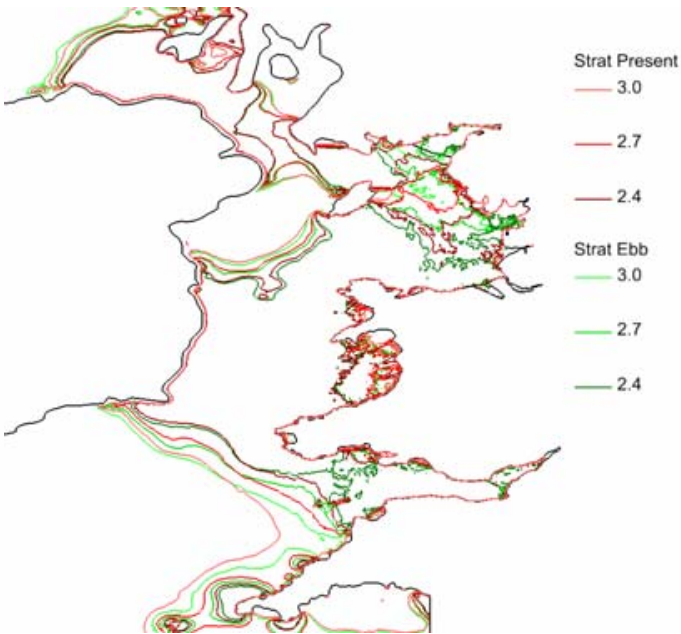

b)

Figure 5 Plot of tidal mixing front locations for: a) present situation overlying stratification parameter; b) $1 x$ DoEn ebb mode simulation; c) 3x DoEn dual mode simulation.

The tidal residuals, within the Irish Sea, are shown in Figure 6. The major features of the generally southward flow along the Northwest coast of England, the clockwise gyre off the Northeast coast of Anglesey and the gyres around the Isle of Man are reproduced well by the model. The residual currents within the large estuaries of the Solway and Morecambe Bay are generally outward flows across the mouth with only small localised inward currents. 


\subsubsection{Barrage resultant changes (1x DoEn Ebb mode)}

The addition of 5 barrages within the Severn, Solway, Morecambe Bay, Mersey and Dee estuaries is simulated when the optimal economic cost of energy production is used to determine the number of turbines and sluice gates and mode of operation within each barrage. This scheme is called the $1 x$ DoEn scheme and is comparable to the schemes determined by the Department of Energy in their 1980's studies of these estuaries for best economic viability (Baker 1986, 1991 and Burrows et al, 2008).

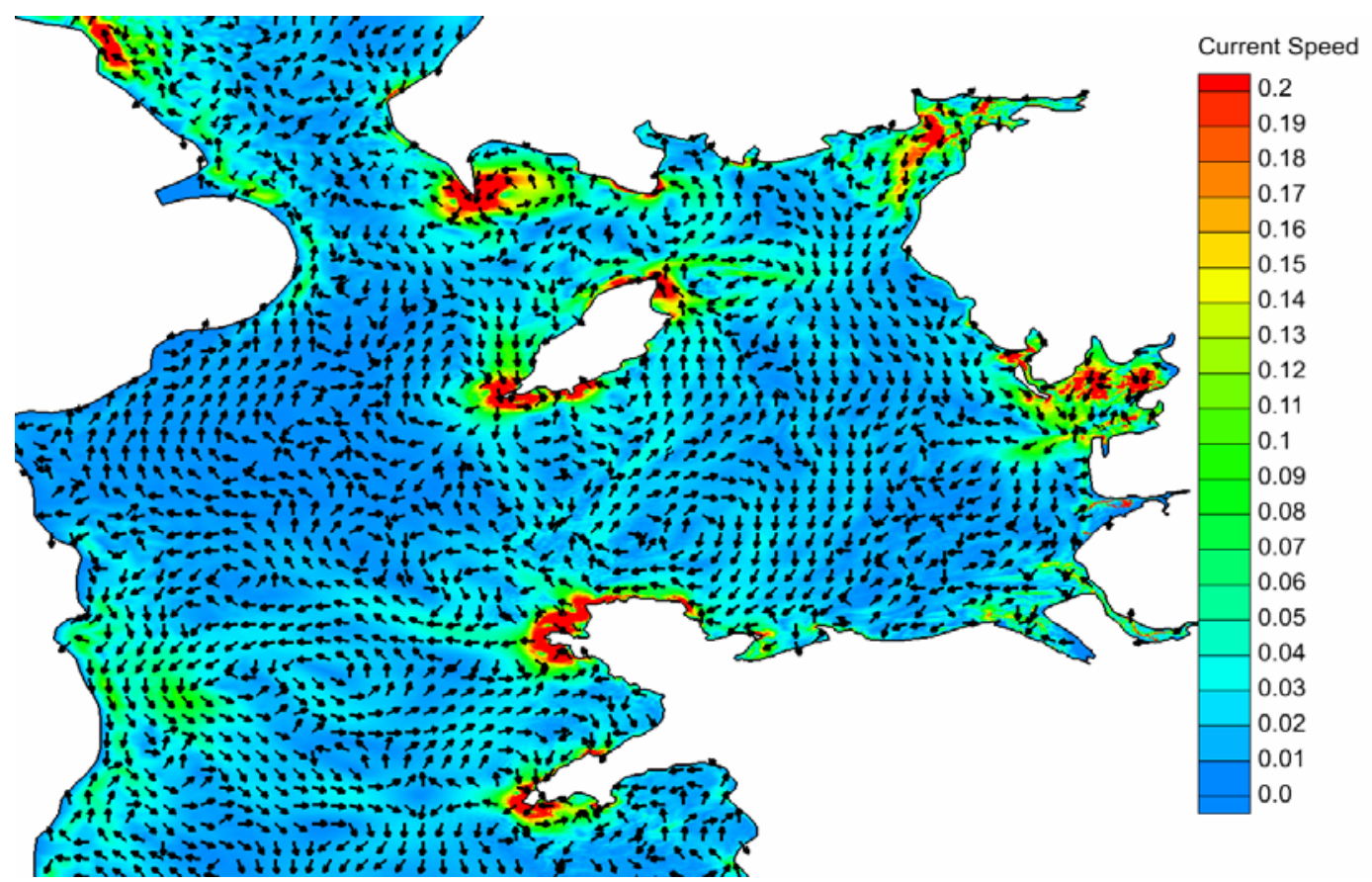

Figure 6 Tidal Residual Currents $(\mathrm{m} / \mathrm{s})$ in present conditions. Wind and Buoyancy residuals not included

The first far field impact to consider is the change in the $M_{2}$ tidal amplitude as shown in Figure 3b). The amplitude is obviously decreased considerably behind the barrages but also the amphidromic point off the east coast of Ireland is shifted slightly. There is a small decrease in tidal amplitude seen to the south of the amphidromic point and across and up the Bristol Channel where the barrage has removed some of the resonance and thus markedly lowered the tidal amplitude. North of the amphidromic point the tidal amplitude increases. In this simulation the increase along the Irish coastline is about $10-15 \mathrm{~cm}$ but this varies depending upon the mode of operation of the barrages.

The change in bottom stress is shown in Figure 4b). It is clear that there is a decrease in bottom stress throughout the Severn estuary and within the basins of the Solway and Morecambe Bay barrage schemes. A decrease is also noted north of the Isle of Man. These decreases are associated with a drop in water speed at these sites and will tend therefore to allow a larger amount of sediment settlement and will also decrease bed scour and re-suspension in these regions.

The changes in location of the tidal mixing fronts are shown in Figure 5b). The exact location of the fronts is affected by the barrages but this remains within the natural variability of the frontal location at present. 


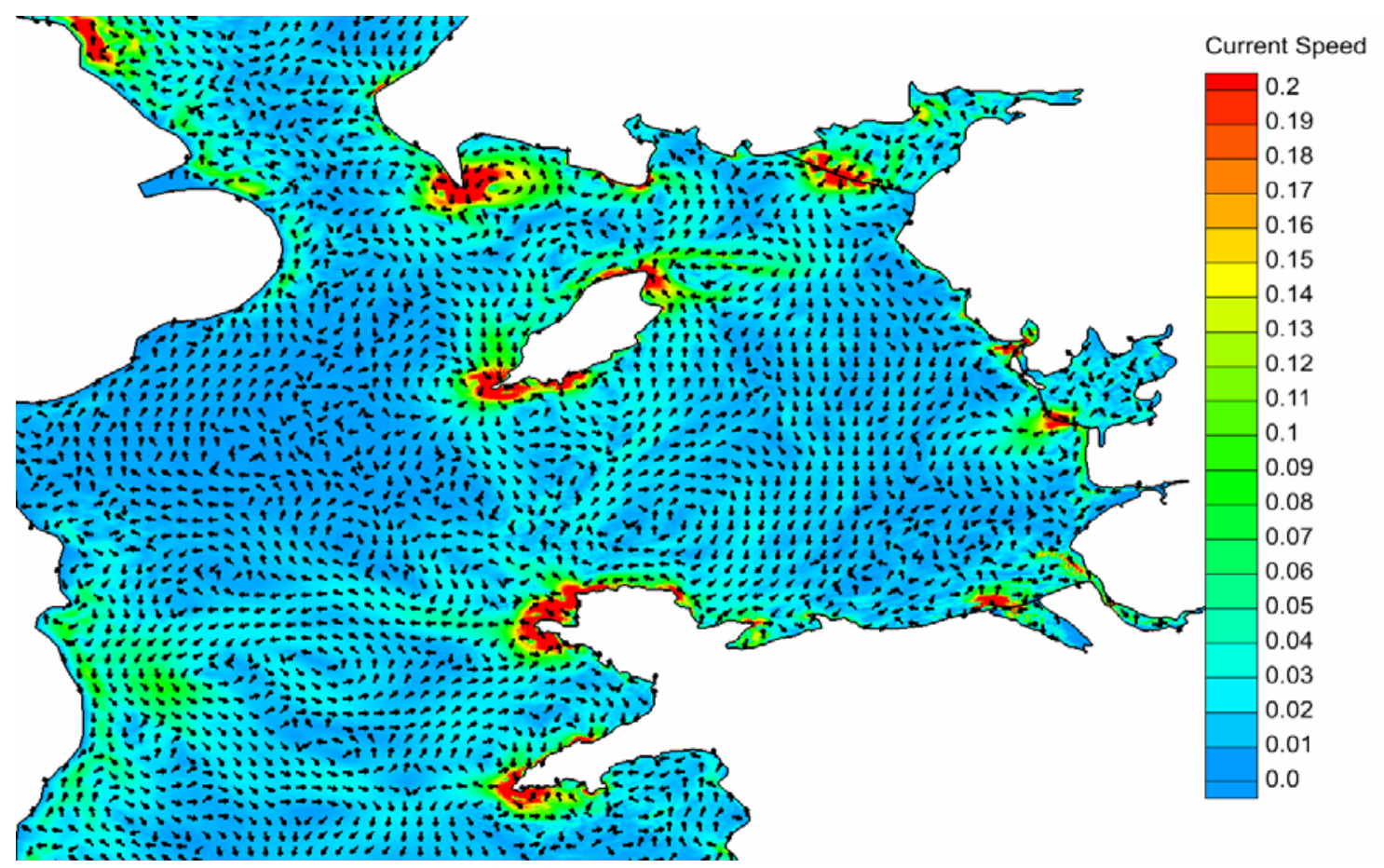

Figure 7 Tidal Residual Currents (m/s) with 1x DoEn Ebb mode.

The residual currents in the Irish Sea, for the 1x DoEn scheme operating in ebb mode, are shown in Figure 7. Through comparison with Figure 6 it is clear that the major changes occur within the vicinity of the barrages. The residual currents are determined mainly by the operation mode and the location of the sluice gates and turbines in the barrages. The inflow through the sluice gates and outflow through the turbines is clearly seen in both the Solway and Morecambe Bay together with the resultant gyres. The Mersey estuary is affected to a much greater extent outside of the barrage than the other barrages due to its upriver location.

\subsubsection{Barrage resultant changes (3x DoEn Dual mode)}

The $3 x$ DoEn scheme is an enhanced turbine scheme whereby three times as many turbines are used than prescribed in the best economic case of the original Department of Energy studies. This results in a larger volume of water passing through the barrages and, when operated in dual (ebb and flood generation) mode, preserves a larger portion of the tidal range within the enclosed basins behind the barrages. This may be considered the best environmental situation, although the economics of energy production deteriorate (Burrows et al, 2008).

The changes to the $M_{2}$ tidal amplitude are shown in Figure 3c). The same qualitative pattern is seen as for the $1 x$ DoEn schemes operating in ebb mode shown in Figure $3 b$ ). In this configuration however the impacts are larger throughout the Irish Sea with an increase along the Irish coast of $15-20 \mathrm{~cm}$ in tidal amplitude (up to $\sim 10 \%$ of baseline).

The changes in bottom stress are shown in Figure 4c). Again this is qualitatively similar to the $1 \mathrm{x}$ DoEn scheme but has a larger quantitative effect. The decrease in bottom stress in the Bristol Channel is up to $30 \%$ larger in this operation mode than in the ebb schemes considered previously. 
The tidal mixing fronts, seen in Figure 5c) again do not move very far, and remain within the natural variability of the present situation, but the range of variability of the Celtic Sea front is quite different from that seen in the $1 \times$ DoEn case and the present situation.

The residual currents in the Irish Sea are shown in Figure 8. The residual currents in the $3 x$ DoEn dual mode simulation very closely match the residual currents in the present conditions. The gyre circulation patterns associated with the $1 \mathrm{x}$ DoEn ebb mode scheme are not present here due to the larger turbine capacity which allows the water to flow through on both the ebb and flood tidal phases. As the turbines are generally situated in the deep water channels, through which the majority of the natural water fluxes occur, the currents associated with the restricted flow regime through the turbines nevertheless matches well with the present conditions.

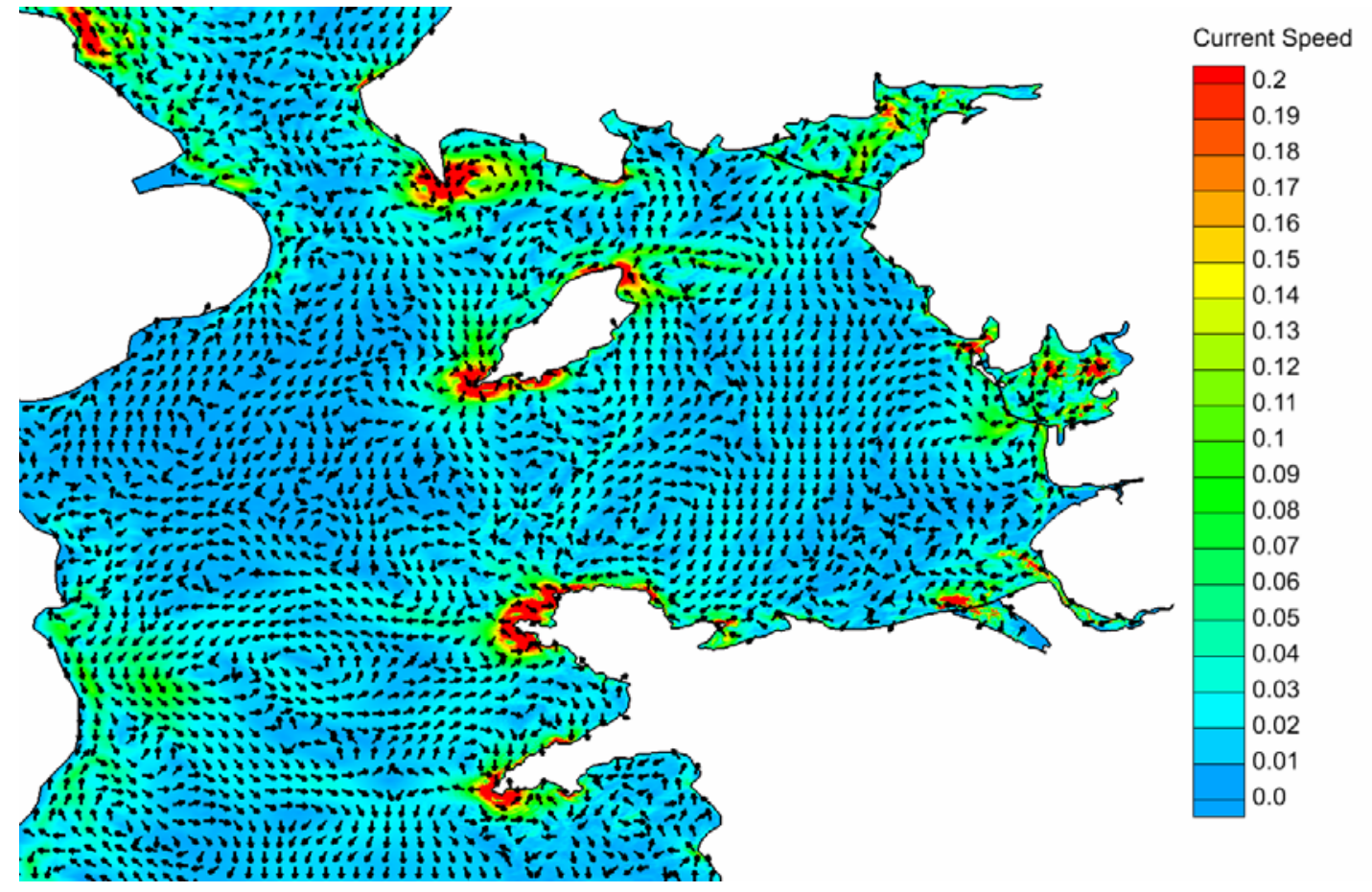

Figure 8 Tidal Residual Currents (m/s) with 3x DoEn Dual mode.

\subsection{Environmental Implications}

The far field environmental implications of the installation of these five barrages are qualitatively similar whichever scheme and mode of operation is chosen. The exact quantitative values of the changes are highly dependent upon the exact scheme and mode of operation chosen for each barrage.

The primary impact of the barrages is the increased flooding risk, due to the increase in tidal amplitude, along the east coast of Ireland and Northern Ireland which is up to $10 \%$ of the present tidal range (near the tidal amphidrome). This is significantly less than the effect of the passage of a typical storm surge event (the 1 in 50 year surge for that area is about $1 \mathrm{~m}$, according to Lowe and Gregory, 2005) but will slightly increase the probability of higher water levels in that area.

The tides in the Bristol Channel are reduced in amplitude and this may help reduce storm surge flooding risks in this area. The impact on the tides in the Irish Sea as a whole is small with a slight 
increase being seen of about $5 \mathrm{~cm}$ on average across the region under the $1 \times$ DoEn ebb mode scheme and $10 \mathrm{~cm}$ for the $3 x$ DoEn scheme in dual mode.

The reduction in bottom stress seen in the Bristol Channel has implications for the sediment regime in this area. The reduced bottom stress and associated velocities mean that the water column will become less turbid and allow more light penetration. It will also permit a greater biodiversity in the benthic habitat as the velocities at the sea bed reduce (Kirby and Retière, 2007).

The stratification of the Irish and Celtic Seas and location of the tidal mixing fronts remains largely unchanged by the inclusion of the barrages which means that these regions of high primary production will remain in the same locations.

The residual currents within the region are only significantly affected in the locality of the barrages. The largest extent of effect away from the barrage is seen in the Mersey Estuary due to its upriver estuarine location rather than its being located at the mouth of the estuary.

\subsection{Changes within estuaries and near-field effects}

The main impacts which have been identified by many conservation groups are the changes in inter-tidal area from the undisturbed situation and the impact upon the fish, invertebrate and bird populations within the estuaries. It is clear that there will be a reduction in the intertidal mud-flats due to the construction of an estuarine barrage. These provide important habitats for many species and feeding grounds for birds.

The 0-D model results identified the potential for amelioration of this effect by use of dual-mode operation and increased turbine capacity which would act to increase the tidal range within the basin relative to ebb mode (although this would increase the cost of electricity generated).

A barrage will block the entry of longer period swell waves but local generation of waves within an estuary can still impact on intertidal areas (Wolf, 2003 and 2004; Möller and Spencer, 2002 and 2003). Raised low water level can increase the effective time averaged fetch within an estuary (Gray, 1992) and thereby increase the impact of the waves generated within a barraged area compared to any present situation.

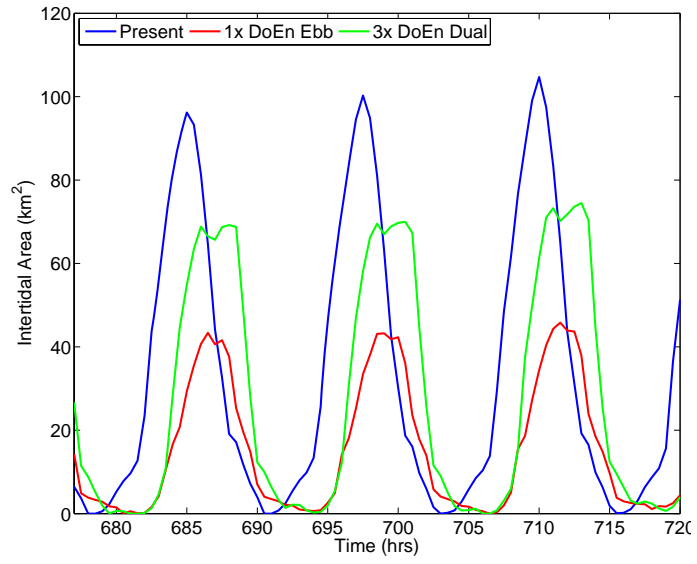

a)

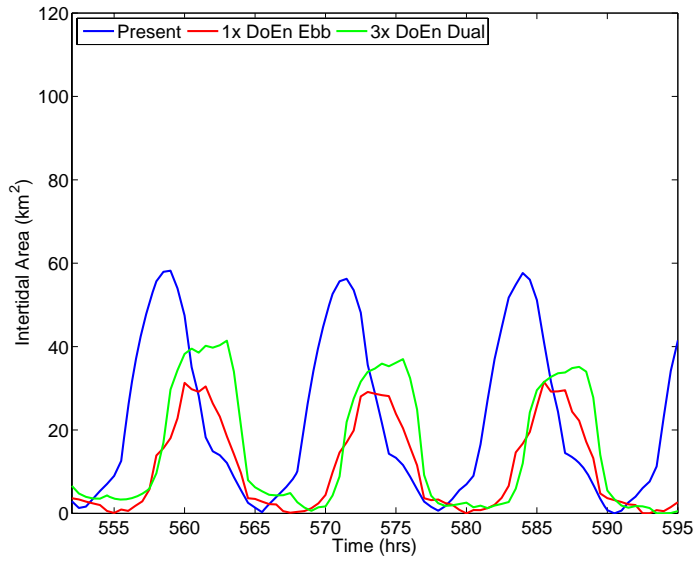

b)

Figure 9 Intertidal area of Severn barrage basin for a typical: a) spring tide; b) neap tide.

The 2-D ADCIRC model has been used to calculate more accurately the change in intertidal area. These numbers are highly dependent upon the available bathymetry for which the Mersey and Dee have excellent high resolution LiDAR data whilst the others are coarse with little vertical 
resolution above mean water level. Thus the quantitative results shown should be understood with this in mind. Examples of the intertidal areas for different installation and operation scenarios are shown in Figure 9 to Figure 11 for the Severn, Mersey and Dee estuaries.

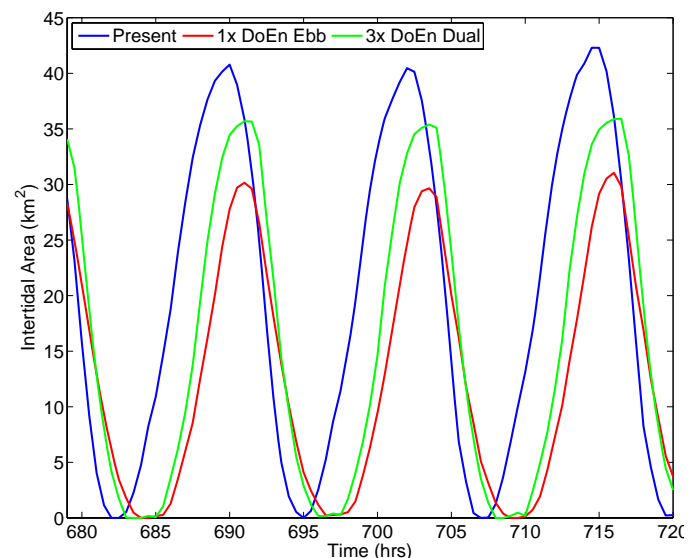

a)

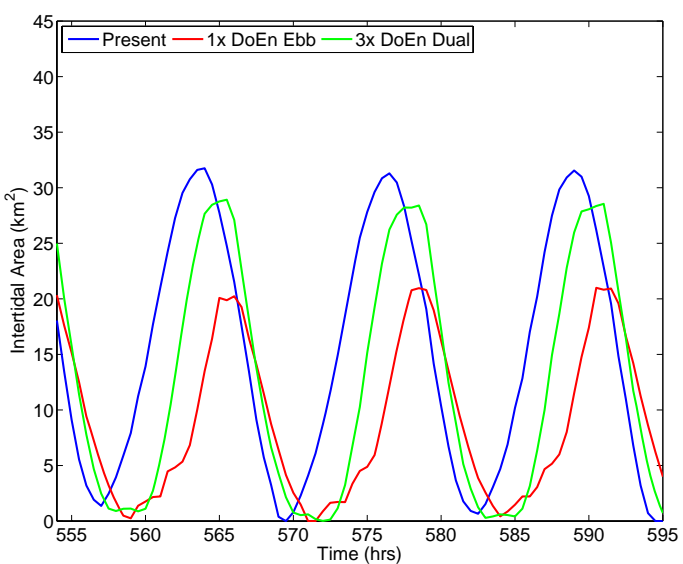

b)

Figure 10 Intertidal area of Mersey barrage basin for a typical: a) spring tide; b) neap tide.

The relative changes in intertidal area are seen to change from spring to neap tides and from site to site depending upon the underlying bathymetry. What is consistent throughout the simulations is the phase shift in the intertidal dynamics. This is due to the barrage operation requiring the tides to be held back to generate a head difference for power production.

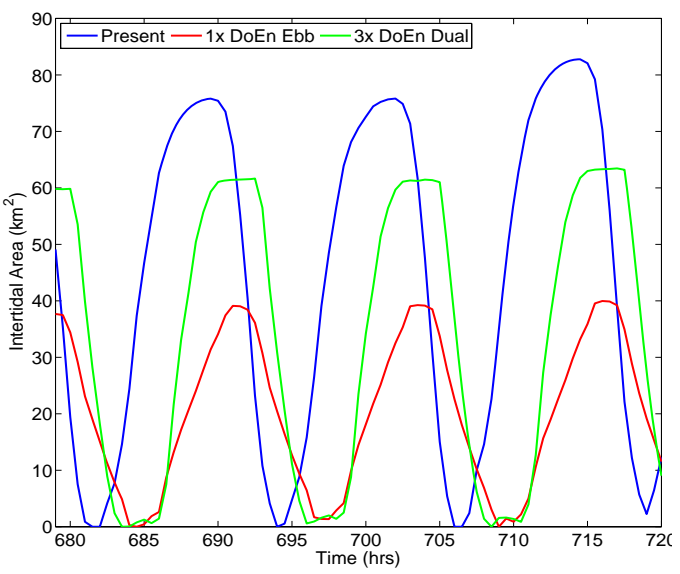

a)

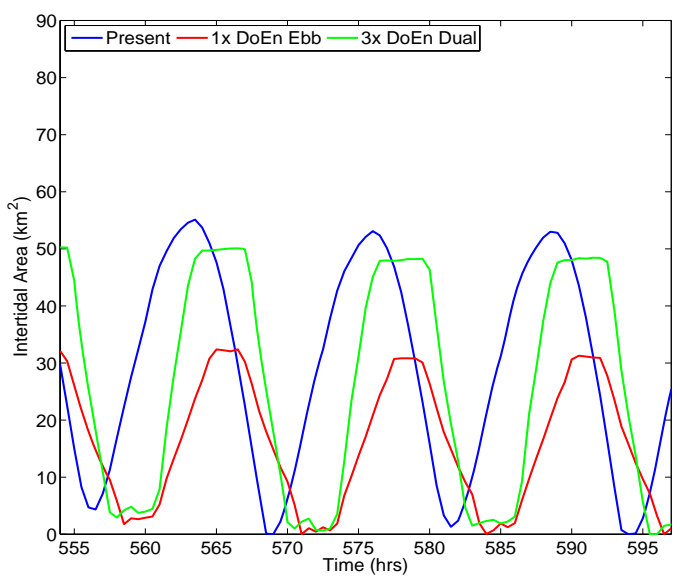

b)

Figure 11 Intertidal area of Dee barrage basin for a typical: a) spring tide; b) neap tide.

The maximum intertidal area is shown below in Figure 12a) to provide a simple visual comparison of the impact of the barrages. This reveals that increasing the installed turbine capacity in dual mode does have a marked increase in the maximum intertidal area retained within the basin area. The specific maximum area retained by any given scheme is highly dependent upon the bathymetry of the enclosed basin and no general statement for all barrage enclosed regions can be made. 
These numbers are within the enclosed basins only and do not include the effect on the maximum intertidal area outside of the basin. For most of the barrage schemes the latter effect is negligible, but for the Severn and Mersey barrages there is a marked impact on tidal amplitudes for a distance seaward of the barrage.

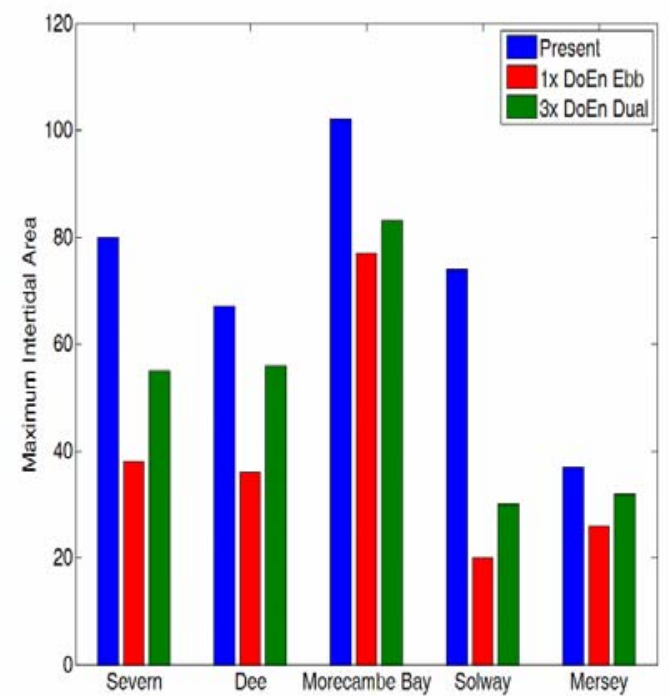

a)

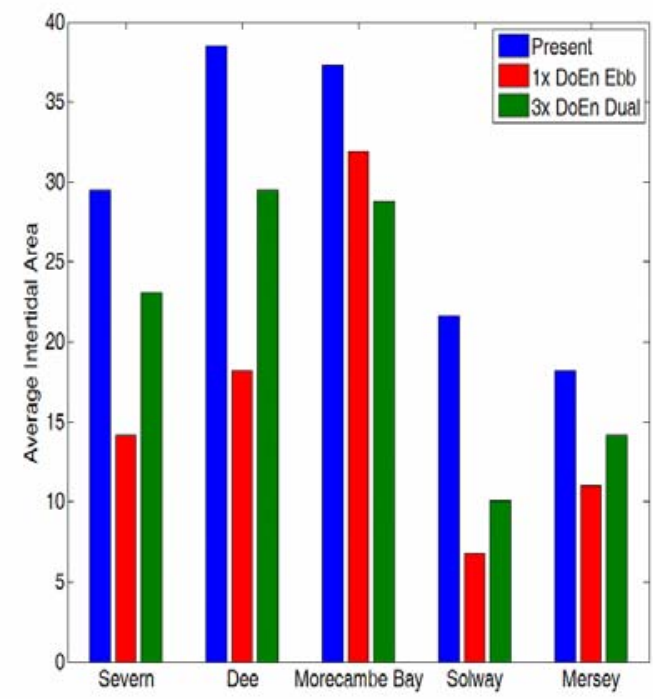

b)

Figure 12 Intertidal area for each basin as: a) maximum extent; b) average available.

It is also instructive to consider the average amount of 'mudflats' available. By integrating the total area and dividing by the length of simulation time we arrive at an average area of mudflat exposed, as shown above in Figure 12b). The anomalous result for the Morecambe Bay barrage may suggest the requirement for better bathymetry within this region. With the exception of the Solway, the percentage area retained for the $3 \times$ DoEn scheme is remarkably consistent at $\sim 75 \%$ of the undisturbed area.

\section{Conclusions}

The introduction of tidal barrages into 5 major estuaries along the west coast of the UK has a wide range of potential impacts. Here we have attempted to quantify these impacts using 0-D and 2-D models. The largest potential impact at the far field scale is the increase in tidal amplitude along the east coast of Ireland possibly leading to enhanced coastal flood risk. There is little other far field impact of any importance seen using the 2-D model, although future studies using 3-D models may identify impacts not currently modelled.

Locally to all the barrages there are reductions in tidal range and within the impounded basins there are even greater decreases. A general loss of intertidal habitat is observed within the basin regions which will have an impact upon the carrying capacity of the estuaries for birds.

There is an associated change in bottom stress with each barrage which will impact upon the benthic habitats at each site, although this is site specific in its quantitative effect. The reduced turbidity in the Bristol Channel and Severn Estuary may lead to an increase in bio-diversity in the benthic habitat.

The impacts upon the local environment can be reduced if a larger installed turbine capacity is used in dual mode operation. This mode of operation is shown to retain a large percentage of the 
present tidal range within the basin area. The use of the turbines for pumping, to enhance head differences prior to electricity generation, will help to reduce the impacts within the basin and also increase the power potential of the barrages.

\section{Acknowledgements}

The work reported herein has been undertaken as part of project JIRP 106/03 funded over the period 2006-2008 by the Northwest Regional Development Agency through the Joule Centre. The views expressed are, however, those of the authors and do not necessarily reflect those of the sponsors or the host institutions in which the work was conducted.

We would like to thank student Toby Gurran for his work in identifying sources of information on environmental impacts, during his Nuffield bursary placement at POL in July-August 2008

\section{References}

Aldridge, J.N. 1997 Hydrodynamic model predictions of tidal asymmetry and observed sediment transport paths in Morecambe Bay. Estuarine, Coastal and Shelf Science, 44: 39-56.

Aubrey, A. and Elliott, M. 2006 The use of environmental integrative indicators to assess seabed disturbance in estuaries and coasts: Application to the Humber Estuary, UK. Marine Pollution Bulletin, 53, 175-185

Baker A.C. 1986 The development of functions relating cost and performance of tidal power schemes and their application to small-scale sites, in Tidal Power, Thomas Telford, London.

Baker A.C. 1991 Tidal Power, Peter Peregrine, 250pp.

BERR 2008, Severn Tidal Power Feasibility Study: Strategic Environmental Assessment, April (www.berr.gov.uk/files/file46064.pdf).

Boesch, D.F and Paul, J.F. 2001 An overview of coastal environmental health indicators. Human and Ecological Risk Assessment, 7,5, 9pp.

Burrows, R., Walkington, I.A., Yates, N.C., Hedges, T.S., Li, M., Zhou, J.G., Chen, D.Y., Wolf, J., Holt, J. and Proctor, R. 2008 Tapping the tidal power potential of the Eastern Irish Sea, Final report on Joule Centre project JIRP106/03, Department of Engineering, University of Liverpool, UK, December 2008.

Burrows, R., Walkington, I.A., Yates, N.C., Hedges, T.S., Li, M., Zhou, J.G., Chen, D.Y., Wolf, J., Holt, J. and Proctor, R. 2009 Tidal energy potential in UK waters, this volume.

Carroll, B., Li, M., Pan, S., Wolf, J. and Burrows, R. 2008 Morphodynamic impacts of a tidal barrage in the Mersey Estuary. Proceedings of ICCE 2008. Hamburg, August 31 September 5, 2008.

Dyer, K.R. and Huntley, D.A. 1999 The origin, classification and modelling of sand banks and ridges. Continental Shelf Research, 19, 1285-1330.

Elliott, M., Boyes, S.J. and Burdon, D. 2006 Integrated marine management and administration for an island state-the case for a new Marine Agency for the UK. Marine Pollution Bulletin, $52,469-474$.

Fong, S.W. and Heaps, N.S. 1978 Note on quarter-wave tidal resonance in the Bristol Channel. Institute of Oceanographic Sciences Reports no. 63.

Gordon, D.C. 1994 Intertidal ecology and potential power impacts, Bay of Fundy, Canada Biological Journal of the Linnean Society, 51: 17-23.

Gray, A. (ed.) 1992 The ecological impact of estuarine barrages. British Ecological Society, Ecological Notices, no. 3, 46pp.

Hao, W., Jian, S., Ruijing, W., Lei, W. and Yi'an, L. 2003 Tidal front and the convergence of anchovy (Engraulis japonicus) eggs in the Yellow Sea. Fisheries Oceanography, 12,4-5, 434442.

Hench, J.L. and Luettich, R.A. 2003 Transient tidal circulation and momentum balances at a shallow inlet. Journal of Physical Oceanography, 33, 913-932. 
Hodd, S.L. 1977 Environmental considerations of a Fundy tidal power project. Pp. 71-81 in 'Fundy Tidal Power and the Environment', proceedings of a workshop on the Environmental Implications of Fundy tidal power. Wolfville, Nova Scotia, Nov 4-5, 1977, ed. G.R.Daborn.

Holt, J.T., James, I.D. and Jones, J.E. 2001 An s-coordinate density evolving model of the North West European Continental Shelf. Part 2 Seasonal currents and Tides. Journal of Geophysical Research, 106, C7: 14035-14053.

Jones, J.E., Hall, P. and Davies, A. M. 2008 An intercomparison of tidal solutions computed with a range of unstructured grid models of the Irish and Celtic Sea Regions. Submitted to Ocean Dynamics.

Kirby, R. 1987 Changes to the fine sediment regime in the Severn Estuary arising from two current barrage schemes, pp. 221-234 in 'Tidal Power', Proceedings of the symposium organized by the Institute of Civil Engineers, 30-31 October, 1986. Thomas Telford, London.

Kirby, R. and Shaw, T.L. 2005 Severn Barrage, UK - environmental reappraisal. Proceedings of the Institution of Civil Engineers, Engineering Sustainability 158, March 2005 Issue ES1, 3139.

Kirby, R. and Retière, C. 2007 Comparisons between environmental and water quality issues at the tidal power scheme at La Rance, France and those expected in the Severn Estuary, UK. Unpublished $\mathrm{m} / \mathrm{s}$ 28pp.

Leuttich, R.A. and Westerink, J.J. 1995 Continental shelf scale convergence studies with a barotropic tidal model. In: Lynch D.R. and Davies A.M. (ed). Quantitative skill assessment for coastal ocean models, published by American Geophysical Union, pp. 349-411.

Lowe, J.A. and Gregory, J.M. 2005 The effects of climate change on storm surges around the United Kingdom. Philosophical Transactions of the Royal Society. Series A, Mathematical and Physical Sciences, 363, 1313-1328. doi:10.1098/rsta.2005.1570

Matthews, M.E. and Young, R.M. 1992 Environmental impacts of small tidal power schemes, pp. 197-214 in 'Tidal power: trends and developments, Proceedings of the 4th conference on Tidal Power, organized by the Institute of Civil Engineers, 19-20 March, 1992. Thomas Telford, London.

Miles, G.V. 1982 Impact on currents and transport processes pp. 59-64 in 'Severn Barrage', proceedings of symposium held by Institution of Civil Engineers, London, 8-9 Oct 1981, Thomas Telford Ltd.

Möller, I. and Spencer, T. 2002 Wave dissipation over macro-tidal saltmarshes: Effect of marsh edge typology and vegetation change Journal of Coastal Research Special Issue 36:506-521

Möller, I. and Spencer, T. 2003 Wave transformations over mudflat and saltmarsh surfaces on the UK East coast - Implications for marsh evolution. Proceedings of the International Conference on Coastal Sediments '03, Florida, USA.

Odd, N.V.M. 1982 The feasibility of using mathematical models to predict sediment transport in the Severn Estuary, pp. 195-202 in 'Severn Barrage', proceedings of symposium held by Institution of Civil Engineers, London, 8-9 Oct 1981, Thomas Telford Ltd.

Parker, W.R. and Kirby, R. 1982 Sources and transport of sediment in the inner Bristol Channel and Severn Estuary pp. 181-194 in 'Severn Barrage', proceedings of symposium held by Institution of Civil Engineers, London, 8-9 Oct 1981, Thomas Telford Ltd.

Pierre, J. 1993 Tidal energy: promising projects - La Rance - a successful industrial scale experiment, Proc IEEE Trans Energy Conversion, 8(3), 552-558.

Pingree, R.D. and Griffiths, D.K. 1979 Sand transport paths around the British Isles resulting from M2 and M4 tidal interactions. Journal of Marine Biological Association of the United Kingdom 59, 497-513.

Pingree, R.D. and Maddock, L. 1979 The tidal physics of headland flows and offshore tidal bank formation, Marine Geology, 32, 269-289

Radford, P.J. 1982 The effects of a barrage on water quality, pp. 203-208 in 'Severn Barrage', proceedings of symposium held by Institution of Civil Engineers, London, 8-9 Oct 1981, Thomas Telford Ltd.

Sharples, J. 2008 Potential impacts of the spring-neap tidal cycle on shelf sea primary production. Journal of Plankton Research, 30(2):183-197; doi:10.1093/plankt/fbm088

Shaw, TL, 1980 An environmental appraisal of tidal power stations: with particular reference to the Severn barrage. Shaw (ed.), London: Pitman Advanced Publishing Program, 220pp. 
Shaw, T.L. 1990 Ecological aspects of the Severn barrage, pp. 245-262 in 'Developments in tidal energy', Proceedings of the 3rd conference on Tidal Power, organized by the Institute of Civil Engineers, 28-29 November, 1989. Thomas Telford, London.

Simpson, J. H. and Hunter, J. R. 1974 Fronts in the Irish Sea. Nature, 250, 404-406.

Sustainable Development Commission, 2007, Turning the Tide: Tidal Power in the UK, SDC, Whitehall London (www.sd-commission.org.uk), October.

Wolf, J. 2003 Parametric Modelling of Waves in Liverpool Bay and Dee Estuary. POL Internal Document No. 162.

Wolf, J. 2004 Wave Modelling for the Blackwater Estuary. POL Internal Document No. 167. 12pp. 